\title{
EXPRESSANDO GENERALIZAÇŌES EM LIBRAS: ÁLGEBRA NAS MÃOS DE APRENDIZES SURDOS
}

\author{
Solange H. A. Fernandes* \\ Lulu Healy ${ }^{* *}$
}

\begin{abstract}
RESUMO: Neste artigo exploramos as práticas matemáticas de aprendizes surdos. Mais especificamente, procuramos identificar como aprendizes que tem a Língua Brasileira de Sinais (Libras) como primeira língua, uma língua visuogestual, expressam generalizaçōes matemáticas. Começamos com um breve histórico de como esta língua integrou-se a educação dos surdos. Na sequência, apresentamos alguns construtos oriundos da Psicologia Soviética que orientam nossas atividades de pesquisa. Finalmente, a partir de evidências procedentes do trabalho de um grupo de alunos surdos envolvidos em tarefas de generalização de padrões, analisamos a emergência do pensamento algébrico em suas práticas matemáticas.

Palavras-chave: Alunos surdos. Pensamento algébrico. Língua de sinais. Práticas matemáticas. Generalização.
\end{abstract}

Academia Paulista Anchieta, Universidade Anhanguera Bandeirante (Uniban). São Paulo (SP) Brasil.

** Academia Paulista Anchieta, Universidade Anhanguera Bandeirante (Uniban). São Paulo (SP) Brasil.

Contato com as autoras: <solangehf@gmail.com>

Cad. Cedes, Campinas, v. 33, n. 91, p. 349-368, set.-dez. 2013

Disponível em <http://www.cedes.unicamp.br> 


\title{
EXPRESSING GENERALIZATIONS IN LIBRAS: ALGEBRA IN THE HANDS OF DEAF LEARNERS
}

\begin{abstract}
The paper explores the mathematical practices of deaf learners. More specifically, it aims to identify how learners whose first language is Libras (Brazilian Sign Language), a visual-gestural language, express mathematical generalizations. It begins with a brief history of how sign languages have come to be integrated in the education of deaf learners. This is followed by the introduction of some constructs from Soviet Psychology which has informed our research activities. Finally, we present snapshots of the practices which emerged as a group of deaf learners worked with activities involving pattern generalization, and analyze the evidences of algebraic thinking in their mathematical practices.
\end{abstract}

Key words: Deaf students. Algebraic thinking. Sign language. Mathematical practices. Generalisation.

\section{A linguagem e os aprendizes surdos}

$\mathrm{V}$

ivemos num mundo plural, um mundo composto por uma diversidade de culturas, linguagens e línguas. Uma das formas que nos faz reconhecer as diferentes culturas que convivem no mesmo contexto social é perceber o pluralismo de linguagens que nos circunda. Cada uma dessas culturas tem suas próprias práticas linguísticas a oferecer, seja ela verbal, corporal, pictórica ou outra, sendo essas práticas representativas de determinado grupo social. Há consenso entre os educadores que a linguagem tem papel central no sentido de fazer acontecer o cotidiano escolar. Nas aulas de matemática, ao lado das línguas naturais, aprendizes devem também lidar com o discurso matemático. A complexidade associada a atender diferentes práticas linguísticas ao mesmo tempo resulta em certa tensão no contexto escolar. Essa tensão é particularmente evidente quando consideramos as experiências de aprendizes surdos.

A trajetória histórica relativa à educação dos surdos coloca a linguagem, ou melhor, o tipo de língua a ser empregada na prática educativa, no cerne da questão. O debate é frequentemente polarizado entre o uso de métodos manuais (sinais) versus o método oral, uma polarização que pode ser delineada a partir do século XVIII. De um lado estava o francês Abbé de L'Epée, que elaborou um sistema de sinais formalizado - Sinais Metódicos - a partir 
dos sinais usados pelos surdos de Paris, e que em 1760 fundou na França a primeira escola pública para surdos, o Instituto Nacional para Surdos-Mudos na qual o seu sistema era usado. De outro lado tínhamos o educador alemão Samuel Heinicke que, no mesmo período, estava desenvolvendo um método oral para ensinar pessoas surdas a falar. Heinicke oferecia forte resistência ao método usado por L'Epée, provocando um rompimento ideológico entre eles, o que se torna evidente nas correspondências trocadas entre dois (MOURA, 2000). Após a morte de L’Epée em 1789, os defensores do oralismo passaram a fazer duras críticas à instrução dos surdos baseada unicamente no uso de sinais. Quase um século depois, como descreve Lang (2003), em 1880 no Congressode Milão, os participantes "votaram no método oral alemão para ser o método oficial utilizado nas escolas de muitas naçôes" (p. 15). Ele também relata que os surdos foram excluídos desta votação. Oralismo, portanto, tornou-se o método dominante e, por muitos anos, os alunos surdos foram desencorajados ou até mesmo proibidos de usar a língua de sinais durante sua vida escolar.

Foi somente nas décadas de 1960 e 1970 que este domínio começou a ser contestado, sobretudo após o reconhecimento científico da American Sign Language (e, consequentemente, das línguas de sinais de outros países por todo mundo) como uma língua verdadeira e natural (STOKOE, 1960/2005). ${ }^{1} \mathrm{Com}$ os questionamentos sobre o oralismo, uma série de outros métodos foram desenvolvidos. Não há espaço suficiente para descrevermos todos eles neste trabalho; basta dizer que nas escolas brasileiras, hoje, sejam elas escolas especiais ou regulares que incluem alunos surdos, uma variedade de métodos são empregados. Na escola em que este estudo foi conduzido, a Língua Brasileira de Sinais (Libras) é considerada a primeira língua do aluno surdo (L1) e a Língua Portuguesa escrita como segunda (L2). Nas aulas de matemática dessa escola, ambas as línguas são usadas simultaneamente, a instrução do professor é oferecida em Libras (por vezes, através de um intérprete) e os trabalhos de texto são apresentados e/ou produzidos escritos em língua portuguesa. Encontramos poucos estudos nos quais o uso dessa abordagem bilíngue foi investigado especificamente em relação à aprendizagem matemática, e nenhum no qual a apropriação de conceitos algébricos foi considerado sob essa perspetiva. Mais atenção tem sido dada à alfabetização e à complexidade de aplicar os princípios de interdependência linguística, provenientes de estudos da aprendizagem da segunda língua (falada) para alunos surdos. A este respeito, tem-se argumentado que, para compreender o processo de alfabetização de alunos surdos, é necessário levar em conta o conjunto de modalidades sensoriais disponíveis. 
Diferentes estímulos sensoriais devem garantir oportunidades para que esses alunos apropriem-se e manipulem todos os meios de mediação à sua disposição (MAYER; AKAMATSU, 2003). Neste trabalho, consideramos o desafio de aprender matemática em Libras. Em particular, questionamos sobre como alunos surdos expressam generalidades matemáticas em Libras e se esse modo de expressão evidencia o pensamento algébrico.

\section{Mediação, linguagem de sinais e aprendizagem matemática}

Nossa abordagem tem sido fortemente influenciada pelo trabalho de Vygotsky e especialmente por suas ideias sobre o papel mediador das ferramentas materiais e semióticas, desenvolvidas principalmente a partir de seus estudos realizados com pessoas com deficiências (VYGOTSKY, 1997). Para ele, a linguagem é um conceito amplo que abrange, além da função comunicativa, a função de organização e desenvolvimento dos processos de pensamento. No entanto, essa posição não representava uma defesa ao oralismo, pois para ele a criança surda não deveria ser vista como uma criança normal que não pode ouvir (idem, ibid.). Criticando o método do oralismo para a educação dos surdos que prevalecia na época, Vygotsky declara que "o ensino do surdo-mudo por esse método é estruturado, precisamente, em contradição com a natureza da criança. É preciso forçar sua natureza para ensinar-lhe a falar" (1997, p. 124).

Em consonância com as ideias defendidas por Vygotsky, Luria (1992) defende que na presença de um defeito inato, várias funções passam a realizar papéis diferentes, tornando-se ferramentas para compensar uma deficiência especifica. Como exemplo, cita a mímica utilizada pela criança surda, que deixa de ser um modo simples de expressar suas emoções e torna-se um meio vital de comunicação.

Em relação à educação dos surdos, Vygotsky (op. cit., p. 117) propõe que seja feita em escolas regulares, pois, para ele, o que diferencia cegos e surdos dos normais é um órgão de percepção que pode ser substituído por outro. Por esse ponto de vista, a educação do cego e do surdo não se distingue de forma substancial da educação da criança normal, sendo os cegos e surdos capazes de realizar em sua plenitude a conduta humana. E mais,

[...] devemos utilizar na prática todas as possibilidades de atividade linguística da criança surda-muda, sem tratar com desprezo a mímica 
[...]. A pedagogia não pode fechar os olhos ao fato de que, excluindo a mímica dos limites da comunicação linguística permitida às crianças surdas-mudas, elimina do seu próprio âmbito uma parte enorme da vida coletiva e da atividade dessas crianças, reforça, aumenta e amplia as resistências para seu desenvolvimento, ou seja, as dificuldades na formação de sua atividade coletiva. [...]. A linguagem desengajada da atividade coletiva das crianças resulta uma língua morta (VYGOTSKY, 1997, p. 233; tradução nossa)

De acordo com Van Der Veer e Valsiner (1996), o otimismo pedagógico de Vygotsky combinava com a ideologia soviética predominante. Para ele, o domínio da linguagem promove mudanças radicais nos sujeitos, principalmente no seu modo de interagir com o meio, possibilitando novas formas de comunicação com os indivíduos e de organização de seu modo de agir e pensar. Uma prática instrucional baseada nesses princípios desempenha bem o seu papel se considerar o indivíduo ativo e interativo no seu processo de construção de conhecimento.

As tendências atuais, ao falar sobre linguagem e aprendizes surdos, aproximam-se da visão de Vygotsky, no sentido de ser aceito que atividades linguísticas podem envolver diferentes modalidades como, por exemplo, as línguas de sinais e as línguas orais. Basicamente, dois sistemas estão relacionados à produção e ao reconhecimento dessas línguas - o sistema sensorial, que utiliza recursos visuais, auditivos e vocais, e o sistema motor, que usa o corpo, mais especificamente as mãos e braços. As línguas de sinais, consideradas as línguas naturais dos surdos, utilizam tanto recursos visuais como motores, ao passo que nas línguas orais predomina o sistema sensorial. De acordo com Goldin-Meadow (2003), a modalidade manual é um meio tão bom quanto a modalidade oral, o que sugere que as capacidades de criar e aprender um sistema linguístico são independentes de sua modalidade. As línguas orais e as das mãos têm estruturas distintas, o que é notável, já que ouvidos e olhos processam as informaçôes de forma diferente.

É importante destacar as elucidações de Vygotsky sobre o processo de conquista da utilização da linguagem como instrumento do pensamento, evidenciando a maneira como o sujeito internaliza as formas de comportamento fornecidas por seu grupo social, a partir da interação com os indivíduos. Por essa perspectiva, o termo linguagem é bastante amplo, pois não se restringe somente às línguas em uso, mas a tudo que envolve significação - tudo que tem o valor semiótico - por ser um instrumento criado e produzido no 
contexto social e na interação entre os indivíduos, servindo como elo entre o cognitivo e o desenvolvimento social (VYGOTSKY, 1987).

Segundo a corrente soviética, então, tanto pensamento como linguagem são resultantes das interações entre indivíduos e seu meio sócio-histórico e cultural (VYGOTSKY, 1962; LEONTIEV, 1978; LURIA, 1992). Leontiev (op. cit.), por exemplo, destaca que o pensamento é um processo natural, mas que não existe fora da sociedade, fora do conhecimento humano acumulado, salientando ainda o vínculo entre o pensamento e a atividade.

O conceito de atividade ${ }^{2}$ defendido por Leontiev (1978) carrega um processo social com o propósito de atingir um objetivo impregnado de significados culturais, que ocorre a partir de ações mediadas por sistemas semióticos ${ }^{3}$ que levam, em si, a história de geraçôes passadas. Desse modo, a atividade é um processo dialético no qual os indivíduos relacionam-se com o meio e com outros indivíduos, adquirindo a experiência humana. É durante esse processo que ocorre a objetificação das ideias (ou pensamentos) que evocam, dirigem e regulamentam a atividade. Como resultado dessa atividade, os objetos externos reconhecidos pelos sentidos adquirem o caráter de objetos de reflexão; em outras palavras, são objetos do pensamento.

\section{A linguagem algébrica e o pensamento algébrico}

Neste artigo, nosso foco é o pensamento algébrico e a linguagem algébrica. Mais especificamente, buscamos nos discursos de aprendizes surdos indícios de que atividades associadas a práticas discursivas favorecem a manifestação de uma zona de emergência do pensamento algébrico. Nos termos de Radford (2010a), esta zona é definida como um espaço (não físico), no qual os aprendizes envolvidos ativamente em práticas interativas (tarefas e diálogos) podem começar a pensar algebricamente mesmo que ainda não estejam recorrendo a signos alfanuméricos. Isto é, um espaço no qual os aprendizes articulam as formas de mediação disponíveis em um processo de transformar objetos conceituais culturais (objetos algébricos) em objetos de consciência.

Orientando-se pela perspectiva vigotskiana, Radford e Roth (2011) discutem o pensamento como resultado de uma práxis reflexiva mediada pelo corpo, signos e ferramentas, ou melhor, como um movimento dialético entre uma realidade constituída histórica e culturalmente e um indivíduo que reflete sobre ela e a modifica, de acordo com suas interpretações e sentidos subjetivos (RADFORD, 2006). Seguindo os passos de Leontiev, Radford 
e Roth (2011) destacam o sentido pessoal que, nas situações instrucionais, emerge da necessidade de distinguir o significado objetivo do significado individual atribuído ao objeto em estudo. Em outras palavras, durante a atividade cada um dos participantes atribui um significado subjetivo ao objeto da atividade que não corresponde necessariamente ao seu significado objetivo.

$\mathrm{Na}$ sequência deste texto, apresentamos episódios nos quais examinamos a interação entre um grupo de alunos surdos com atividades que envolvem generalização. ${ }^{4} \mathrm{Em}$ cada exemplo, procuramos evidências, nas expressões dos alunos, do pensamento algébrico, partindo da perspectiva de Radford (2010b), que caracteriza o pensamento algébrico como sendo composto por três elementos interrelacionados: um sentimento de indeterminação, ${ }^{5}$ uma forma de agir analiticamente com objetos indeterminados e o uso deu um sistema semiótico adequado de apoio às duas características citadas. Como ele, acreditamos que o processo de expressar a generalização realiza-se em camadas de significação, não organizadas hierarquicamente, mas com o seu alcance "entrelaçado com a forma material que usamos para raciocinar e expressar formas gerais (por exemplo, o padrão de sistema semiótico algébrico alfanumérico, língua natural ou coisa semelhante)" (Radford, op. cit., p. 42).

Em seu trabalho, Radford, por língua natural, refere-se à língua oral. Nosso intuito é investigar o uso de expressões em Libras em atividades algébricas e suas relações com os outros meios de expressão. Radford (2010a, 2010b) discute três formas de pensamento algébrico: o contextual, o padrão e o factual. O pensamento algébrico contextual apresenta um caráter essencialmente pragmático, ou seja, as generalizaçōes mantêm estreita relação com o procedimento empírico. No entanto, a coordenação rítmica dos gestos, palavras e signos dirigem-se a um contexto, ou seja, as "fórmulas" descrevem termos gerais de um determinado contexto, mas as variáveis são expressas explicitamente por termos como "o número da figura" - ou seja, a indeterminação é de certa forma articulada. Já o pensamento algébrico padrão caracteriza uma mudança radical no discurso. Os símbolos alfanuméricos, que passam a ser usados para expressar as generalizações, fazem parte de um sistema linguístico (algébrico) que Radford (2010a) classifica como artificial. No entanto, é exatamente isso que garante que essas generalizações possam ter significado e aplicação além da situação particular a partir da qual foram articuladas. $\mathrm{O}$ que no pensamento algébrico 
contextual é denotado por signos dêiticos ou icônicos passa a ser designado por um sistema semiótico de signos alfanuméricos. Quanto ao pensamento algébrico factual (RADFORD, 2010a), este se estrutura a partir de situaçôes e fatos concretos, permitindo que os aprendizes elaborem fórmulas para representar generalizaçôes sem letras ou outras formas de expressar as variáveis explicitamente. Nesta forma de pensamento, a indeterminação apresenta-se tacitamente. $\mathrm{O}$ autor destaca ainda que,

[...] apesar de sua natureza aparentemente concreta, o pensamento algébrico factual não é uma simples forma de reflexão matemática. Ao contrário, [...] ele repousa sobre mecanismos evoluídos de percepção e da coordenação rítmica de gestos, palavras e símbolos. A apreensão da regularidade e da imaginação de figuras no curso da generalização resulta, e permanece ancorado, em um processo sensorial mediado, mostrando a natureza multimodal do pensamento algébrico factual. (Idem, ibid., p. 7)

Em cada uma das três formas de pensamento algébrico há elemento concreto e abstrato. O que diferencia uma das outras é a maneira pela qual a relação entre esses elementos é expressa. Na próxima seção apresentamos indícios nas práticas discursivas de aprendizes surdos, apontando que, quando submerso numa zona de emergência do pensamento algébrico, o sentido pessoal atribuído ao objeto da atividade pode conduzir a uma generalização; uma forma de pensamento algébrico carregado de signos semióticos que expressam a ideia de variáveis algébricas, mesmo sem necessariamente lançar mão de símbolos alfanuméricos.

\section{Procedimento empírico}

Orientando-nos pela metodologia do Design Experiment (COBB et al., 2003), as atividades que temos desenvolvido para aprendizes surdos procuram explorar representaçóes visuais de sequências algébricas que favoreçam práticas reflexivas e discursivas. Reflexivas no sentido de evocar interpretaçóes pessoais, ou melhor, significados subjetivos que possam favorecer as práticas discursivas entre os aprendizes, levando-os a articular seus sentidos pessoais com estruturas algébricas formuladas a partir de situações concretas.

As atividades discutidas neste artigo foram desenvolvidas nas primeiras duas de cinco sessões de uma hora e trinta minutos cada, realizadas em cinco dias, numa classe de nono ano do ensino fundamental de jovens 
e adultos, no período noturno de uma escola do município de Barueri, São Paulo. ${ }^{6}$ A classe era composta por seis alunos surdos com idades que variavam entre 18 e 31 anos. $O$ grupo de pesquisadores inclui o professor de Matemática da turma e contamos com a presença de uma intérprete. As sessóes foram videogravadas e as descrevemos como Atividades I e II.

\section{Atividade I}

A primeira atividade foi planejada com o objetivo de verificar se os aprendizes poderiam reconhecer regularidades em sequências algébricas estruturadas para oferecer principalmente estímulos visuais.

\section{Figura 1}

Primeira sequência

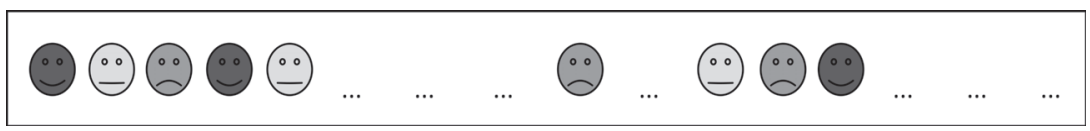

A tarefa consistia, basicamente, em completar a sequência e produzir uma regra que pudesse determinar a posição de cada uma das "carinhas", respeitando sua cor e sua expressão. Neste primeiro contato, não pretendíamos que os alunos escrevessem expressões algébricas para representar os termos da sequência. Nossa intenção era estimular a observação e relatos em Libras, indicando que as carinhas felizes (vermelhas) ocupavam as posições que representam os múltiplos de $3+1$, as carinhas indiferentes (amarelas) representam os múltiplos de $3+2$ e as carinhas infelizes (verdes) os múltiplos de 3 .

Consideramos que iniciar a discussão com os múltiplos de 3 seria mais fácil, por isso as primeiras questôes exploravam as posiçôes das carinhas tristes (verdes). Os alunos envolveram-se na solução da tarefa e participaram ativamente, muitas vezes explicando aos colegas e aos pesquisadores como resolveram as tarefas.

Os alunos perceberam que a sequência repetia-se a cada grupo de três carinhas e a completaram sem dificuldades. É importante ressaltar que alguns impasses foram criados quando os aprendizes tiveram que interpretar a linguagem escrita na proposta da tarefa. A título de exemplo, questōes como “Qual carinha ocupa a posição 6? E a 11?” só foram compreendidas a partir 
da tradução (português - Libras), o que destaca a importância da presença da intérprete para viabilizar a comunicação com os aprendizes. A princípio, os aprendizes mostraram-se confusos entre desenhar seis carinhas e depois 11 carinhas, e desenhar a carinha seis e a carinha 11. A falta do domínio da linguagem escrita provocou certa instabilidade no grupo de aprendizes e, por outro lado, a falta de fluência em Libras gerou certa ansiedade no grupo de pesquisadores.

Um trecho dos discursos dos aprendizes nos despertou especial interesse. Ao identificar que de três em três as carinhas eram tristes, que a antecedente era indiferente e a posterior feliz, Felipe ${ }^{7}$ sinalizou "eu tenho 19 anos e sou feliz, porque 18 é triste e vem antes" (Figura 2). Tal discurso nos mostra que o aprendiz atribuiu um sentido pessoal aos elementos da sequência, que o permitiu determinar um elemento que não aparecia explicitamente na proposta da tarefa.

\section{Figura 2}

\section{9 é feliz}

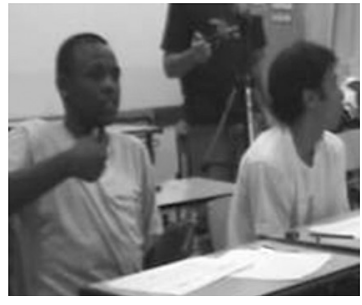

Minha idade

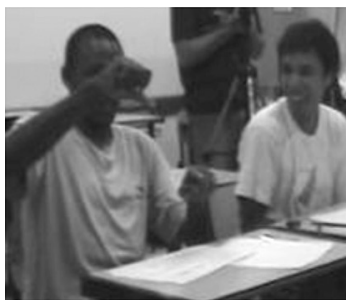

19

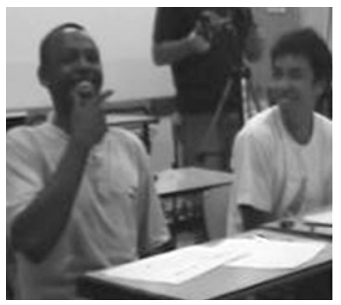

feliz.

Felipe desenvolveu um método que, de fato, poderia ser usado para determinar a posição de qualquer carinha. Esse método consistia em somar grupos de três à posição conhecida de uma determinada carinha triste (ou, às vezes, grupos de 15, quando a diferença era grande) e depois somar mais um para uma carinha feliz e mais dois para uma indiferente. Ele nunca explicou em Libras este método, que conhecemos apenas pelos cálculos que ele deixou marcados no papel. Ele estava então pensando algebricamente? Segundo a definição de Radford (2010b), isso depende se consideramos que ele fazia uso de algum sentido de indeterminação. De fato, embora seu método seja geral, sempre envolve trabalho com valores determinados: aparentemente, nas 
expressões de Felipe, sua forma de agir sobre posições sempre parte de uma posição específica. No entanto, certamente, o forte sentido pessoal de Felipe sobre a relação de dependência entre variáveis dependentes e independentes foi um aspecto importante aqui. Acreditamos que é pouco provável que Felipe usasse seu método para produzir uma expressão nos padrões da álgebra convencional, mas seria possível expressar um objeto indeterminado, talvez uma forma algorítmica, que começou com um mantra de "dado qualquer número". Esta atividade, no entanto, não motivou tal movimento. Notamos também que a estrutura da Libras talvez tenha menos semelhança com a estrutura altamente sequencial e compacta da língua algébrica do que a língua falada. De qualquer modo, nossa interpretação é que Felipe estava engajado em uma forma de pensamento algébrico - o nosso desafio é entender melhor como trabalhar mais explicitamente com a expressão de indeterminação nesta língua.

$\mathrm{O}$ discurso do aprendiz envolveu-o numa zona de emergência do pensamento algébrico que o fez discutir sobre números felizes e tristes. Nossa hipótese é que ele imergiu num pensamento algébrico factual, ou seja, ele elaborou uma forma para reconhecer as expressóes das carinhas sem usar explicitamente letras. Em outras palavras, no discurso do aprendiz a palavra feliz assume para ele o significado de múltiplo de três mais um ou/e 15+1. A estratégia consistia em determinar qual número era representado por uma carinha triste (o múltiplo de três ou 15) mais próximo ao número a ser determinado, um passo na direção de objetificar a noção de variável.

Em discussões sobre a Atividade I no grupo de pesquisa, concluímos que a sequência escolhida não favorecia a observação de uma estrutura figurativa que ajudasse os aprendizes a generalizar. Percebemos que a associação das expressões das carinhas com seus respectivos múltiplos ficou relegada ao segundo plano, ou seja, nas palavras de Radford (2010a), não fazia parte da cultura de sala de aula desses aprendizes organizar o que é percebido de modo a colaborar para a determinação de padrões.

\section{Atividade II}

Com objetivo de levar os aprendizes a reconhecer regularidades em sequências algébricas apresentadas a partir de representações visuais, a nova tarefa consistia em completar a sequência e produzir uma regra que pudesse determinar o número de fios de cabelo de cada um dos filhos da Lulu (Heliel e Fabiane) a cada dia (Figura 3). 
Figura 3

A segunda tarefa

\begin{tabular}{|c|c|c|c|c|c|c|c|}
\hline Heliel & (1) & (4) & (ن) & 0 & 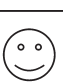 & $\stackrel{\circ}{\bullet}$ & 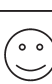 \\
\hline Dia & 1 & 2 & 3 & 4 & 5 & 6 & 7 \\
\hline Fios de cabelo & 3 & 6 & 9 & & & & \\
\hline
\end{tabular}

\begin{tabular}{|c|c|c|c|c|c|c|c|}
\hline Fabiane & (․ㅇ & (1.0.0) & ) & 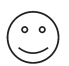 & $\stackrel{\circ}{\ominus}$ & $\stackrel{\circ}{\bullet}$ & $\stackrel{\circ}{\bullet}$ \\
\hline Dia & 1 & 2 & 3 & 4 & 5 & 6 & 7 \\
\hline Fios de cabelo & 5 & 8 & 11 & & & & \\
\hline
\end{tabular}

Continuávamos a explorar os múltiplos de três e de 3+2, mas acreditávamos que a forma que utilizamos para apresentar os termos da sequência pudesse favorecer, mesmo que intuitivamente, a identificação da relação entre o número de fios de cabelos (variável dependente) e o número de dias (variável independente). Os aprendizes não tiveram dificuldades para perceber a sequência de três em três e completar as duas tabelas iniciais. Desenharam os cabelos e foram "contando" três em três. Breno percebeu que bastava multiplicar o dia por três e dividiu sua ideia com o grupo, usando sua linguagem natural (Figura 4). O uso de sinal "sempre" indica que Breno é consciente da generalidade do seu método, mas notamos que na sua articulação a variável "número de dias" ainda não é mencionada explicitamente - ou, para usar os termos de Radford (2010a), a indeterminação permanece tácita.

\section{Figura 4}

A regra de Breno

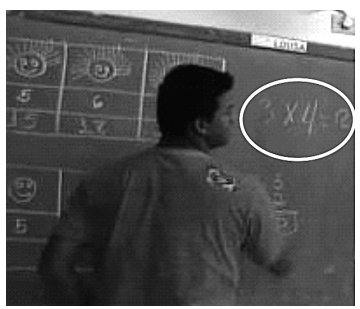

$3 \times 4=12$

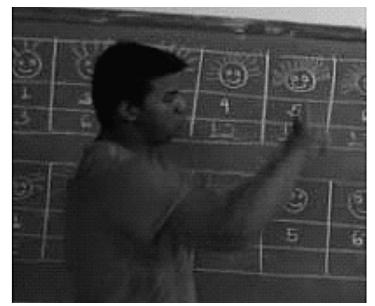

vezes...

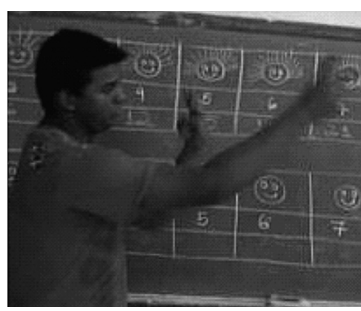

...3 sempre. 
Não houve resistência por parte do grupo para aceitar a estratégia apresentada por Breno, e os aprendizes completaram a primeira coluna de uma terceira tabela (Figura 5) que apresentava os números de dias de forma aleatória. Um a um, os aprendizes foram à lousa, fizeram seus cálculos e completaram o número de fios de cabelo de Heliel (Figura 6).

\section{Figura 5}

A tabela de cabelos

\begin{tabular}{|c|c|c|}
\hline $\mathrm{N}^{\circ}$ de dias & Fios de cabelo Heliel & Fios de cabelo Fabiane \\
\hline 11 & & \\
\hline 15 & & \\
\hline 16 & & \\
\hline 17 & & \\
\hline 20 & & \\
\hline 30 & & \\
\hline 102 & & \\
\hline 1999 & & \\
\hline
\end{tabular}

Figura 6

Completando os fios de Heliel - "sempre vezes três"
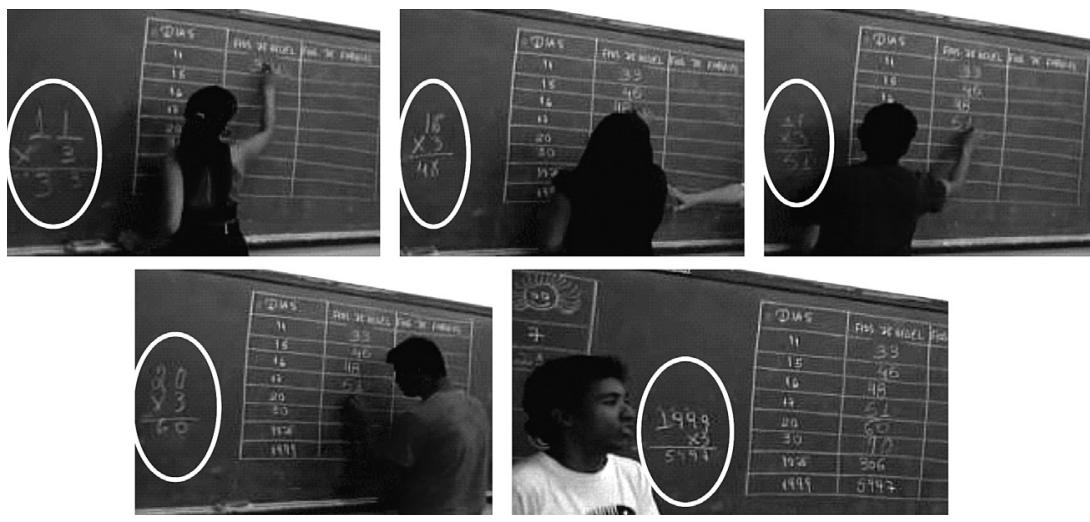

Cad. Cedes, Campinas, v. 33, n. 91, p. 349-368, set.-dez. 2013

Disponível em <http://www.cedes.unicamp.br> 
Mesmo com a tabela preenchida, aparentemente os alunos ainda resistiram à articulação da variável independente e, ao questionarmos se poderíamos determinar uma "regra" para calcular a quantidade de cabelos de Heliel em qualquer dia, os aprendizes não aceitaram o termo "qualquer dia" e nos pediram números específicos. Podemos sugerir que, envolvidos no desafio de resolver a atividade tendo diante de si o "personagem" Heliel, o número de dias deveria ser tal que corroborasse com o sentido pessoal que eles haviam atribuído à tarefa. Afinal, naquele momento todos os personagens apresentados na tarefa estavam diante deles, o que dava a ela o caráter de fato concreto.

Dando sequência a atividade, passamos a discutir a tabela que apresentava o número de fios de cabelo de Fabiane (Figura 3). Inicialmente, a estratégia utilizada pelos aprendizes foi somar três ao número apresentado na célula representando o dia anterior. Possivelmente, tal estratégia tenha sido empregada por influencia da primeira tarefa. Os aprendizes procuraram em seu repertório de operações aritméticas uma que fosse adequada à nova tarefa. De qualquer modo, a estratégia empregada em ambas as tarefas estavam intrinsecamente ligadas a uma situação particular e a cálculos aritméticos. Em relação à determinação de números de fios de cabelos de Fabiane, não podemos dizer que os aprendizes, até este momento, haviam criado uma regra que relacionava dias e fios de cabelo, como aconteceu na tarefa com os fios de cabelo de Heliel. Houve grande mobilização por parte dos pesquisadores no sentido de envolver os aprendizes numa prática reflexiva. Com nossas intervenções e a colaboração da intérprete, Breno percebeu que Fabiane tinha a cada dia dois fios de cabelo a mais que Heliel (Figura 6).

\section{Figura 6}

Percepção de Breno

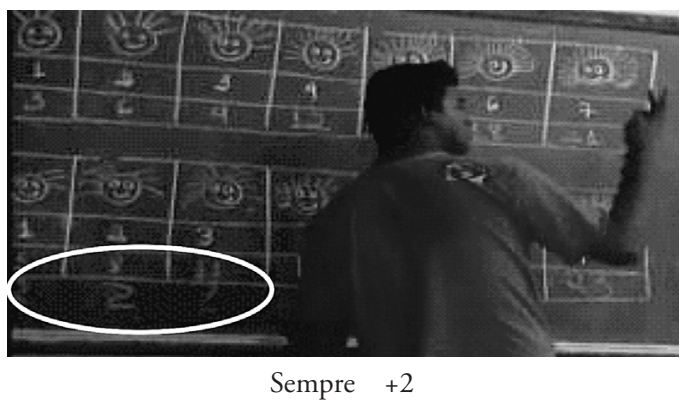


O próximo passo era promover interações entre os aprendizes e desses com os pesquisadores, no sentido de ajudá-los a estabelecer relações entre a "regra" que estruturaram para os fios de cabelo de Heliel e para os de Fabiane.

Várias tentativas foram feitas pelos aprendizes, até que Ana se ofereceu para preencher a segunda linha da Tabela 2 (Figura 5) com o número de fios de cabelo de Fabiane no $15^{\circ}$ dia. Na lousa, ela escreveu a expressão $15 \times 3+2$, efetuou os cálculos, completou a célula da tabela e se voltou para os colegas, quando solicitamos que ela explicasse a todos como chegou ao resultado (Figura 7 ).

\section{Figura 7}

A explicação de Ana

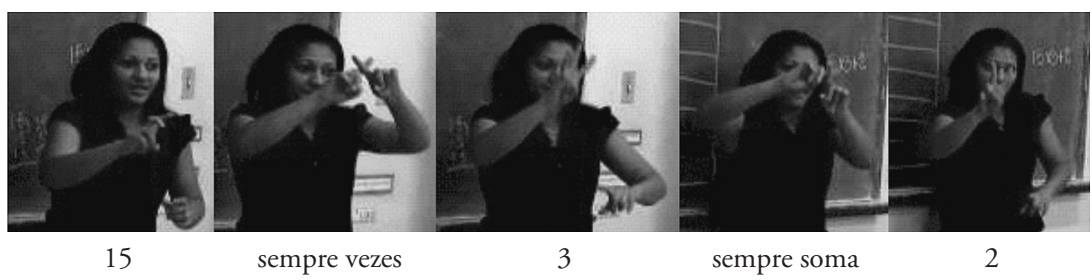

\section{Figura 8}

Uma regra geral

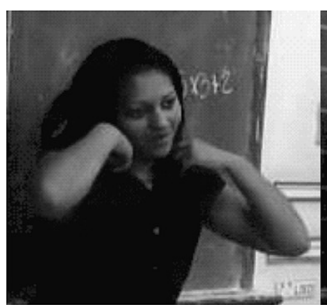

Heliel

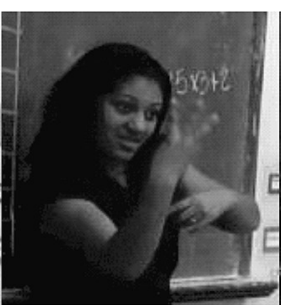

sempre vezes 3

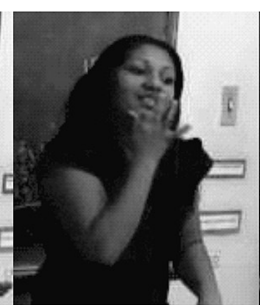

Fabiane

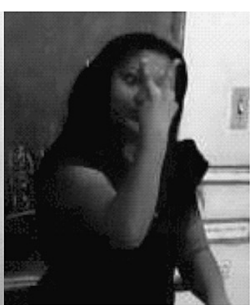

sempre soma 2

Ana diz: 15 sempre vezes três, sempre soma mais 2, o que nos sugeriu que ela percebeu e expressou a regularidade que permitia completar a 
tabela. O uso de sinal "sempre" duas vezes na sua expressão sugere que o método que ela estava propondo tinha uma natureza geral, mesmo que, novamente, o número de dias fosse expresso especificamente. A generalidade do método se confirmou quando Ana foi para o $16^{\circ}$ dia. Dessa vez, ela sinalizou "Heliel sempre vezes 3, Fabiane sempre soma 2", acrescentando uma outra camada a sua explicação. Nós podemos argumentar que a inclusão dos nomes dos personagens é outra indicação da generalidade que ela percebeu (Figura 8). No entanto, sua expressão geral não se refere explicitamente ao número de dias.

\section{Figura 9}

Aplicando sua regra

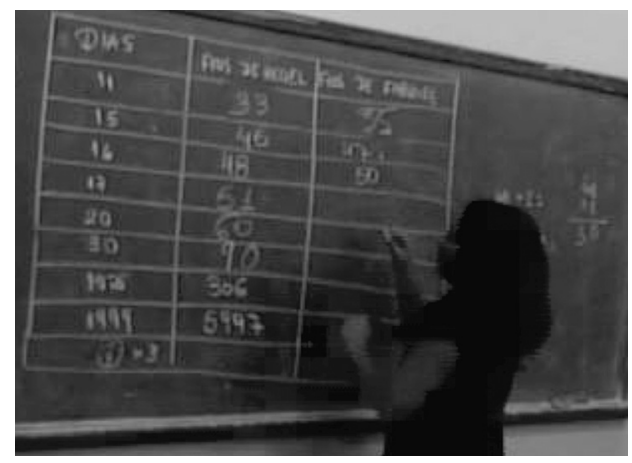

Os indícios apontam que Ana estruturou uma maneira para representar a regularidade das sequências apresentadas que permaneceu conectada à situação particular em que ela estava trabalhando. Isto possibilitou calcular o número de fios para ambos os personagens, em qualquer dia determinado, e sua forma de agir sempre partiu de um dia específico. Embora não haja articulação explícita de indeterminação em relação à variável independente, parecia que Ana estava pensando sobre um caso geral, ao expressar a relação entre o número de fios de cabelo de Heliel e o número de fios de cabelo da Fabiane num mesmo dia. Dentro da perspectiva de Radford (op. cit.), é difícil decidir se a expressão de Ana indica pensamento algébrico contextual ou factual. A principal diferença entre estas formas de pensamento reside na expressão explícita ou não de indeterminação. Contudo, nos exemplos 
apresentados por Radford (2010a, 2010b), essa indeterminação sempre se refere à variável independente - o que não aconteceu neste caso. Em contraste aos exemplos de Radford, nos quais as expressões características de pensamento algébrico contextual têm uma estrutura mais próxima da álgebra convencional que as expressões de pensamento algébrico factual, a tradução da expressão de Ana para a língua algébrica não seria trivial. Cabe destacar que, independentemente da forma de seu pensamento, a "fórmula" da Ana representa uma solução completamente válida para a tarefa. Além disso, sua expressão foi aceita pelos colegas, que juntos completaram a tabela (Figura 9).

\section{Reflexões sobre as generalizações dos aprendizes surdos}

Neste artigo, apresentamos as generalizações matemáticas de um grupo de alunos surdos enquanto esses interagem principalmente através de Libras. Ao longo das duas sessões, há evidências nas generalizaçōes expressas por eles que refletem um modo de pensar algebricamente, mesmo que ainda não recorram à língua algébrica convencional. Evidências ainda apontam que os alunos ficam mais propensos a procurar maneiras de relacionar dois conjuntos de variáveis. Ou seja, os alunos envolveram-se numa zona de emergência do pensamento algébrico, no qual o processo de objetificação inicia-se e objetos culturais ganham sentidos pessoais e subjetivos. No entanto, em termos de sentido de indeterminação citado por Radford (2010b) como um elemento crítico do pensamento algébrico, nossas evidências sugerem que nenhuma das tarefas apresentadas neste artigo, nem as intervenções dos pesquisadores foram suficientes para estimular no discurso o uso de práticas que tornem visíveis objetos indeterminados.

Talvez um dos problemas que os alunos vivenciaram foi que, apesar da narrativa da tarefa ser expressa em linguagem natural (Libras), através de valores numéricos e visualmente, as relações matemáticas não foram destacadas por meios visuais. Em outras palavras, se os cabelos novos fossem visualmente agrupados em conjuntos de três, talvez a estrutura do termo geral ficasse mais evidente. No entanto, mesmo sem a presença de uma estrutura visual e embora os alunos achassem as atividades desafiadoras, em ambas as tarefas, conseguiram desenvolver métodos que lhes permitiram calcular todos os casos específicos propostos. Entretanto, salientamos 
que na elaboração desses métodos os alunos não sentiram necessidade de mencionar explicitamente o desconhecido. Talvez possamos argumentar que a forma simultânea de comunicação favorecida pela Libras seja mais distante da forma sequencial da álgebra em comparação com a língua falada, mas na verdade a expressão de Ana é muito parecida com uma generalização em língua falada.

Parece-nos mais provável que a escassez de expressões que denotem variáveis tem relação com o fato dos alunos não estarem familiarizados com um sistema semiótico, no qual objetos numéricos indeterminados poderiam ser expressos prontamente e, assim, a tendência deles foi interpretar o objetivo da atividade como o desafio de criar métodos para calcular um conjunto específico de valores (essencialmente o que lhes foi solicitado!). Portanto, não deveria ser tão surpreendente o fato de que eles não tenham sido motivados a incluir aspectos de um novo discurso matemático em suas práticas. Radford (2010b) argumenta que não podemos separar o alcance de uma generalização matemática das ferramentas pelas quais ela é expressa. Concordamos, mas gostaríamos de acrescentar que, independentemente da forma com que os alunos se comunicam, seja por meio de sinais ou de língua oral, nosso desafio como educadores de matemática é encontrar contextos nos quais as interpretaçóes dos objetivos da atividade estimulem os alunos a se apropriarem de tais ferramentas. Vemos isso como nosso próximo passo.

\section{Notas}

1. Atualmente, de modo geral, a modalidade manual é aceita como uma língua tão boa quanto a modalidade oral (ver, por exemplo, GOLDIN-MEADOW, 2003).

2. De acordo com Leontiev (1978), a atividade envolve um objeto intencional (material ou ideal) que evoca e dirige as ações do sujeito sobre o objeto, ou seja, a atividade tem como princípio a ação mediada do sujeito orientada a um objetivo.

3. Esses sistemas semióticos contemplam artefatos, corpo (através da percepção, gestos e movimentos), linguagem, signos, entre outros aspectos (RADFORD, 2006).

4. Essa pesquisa foi realizada no âmbito do Projeto Rumo à Eduação Matemática Inclusiva, desenvolvido com o o apoio da Capes (n. 23038.019444/2009-33).

5. Nossa tradução do termo "indeterminacy" (RADFORD, 2010b).

6. Este experimento faz parte de uma série que está sendo realizada com o apoio da Capes (Projeto n. 23038.019444/2009-33).

7. Os nomesdos os alunos citados neste artigo foram mudados. 


\section{Referências}

COBB, P. et al. Design experiments in educational research. Educational Researcher, v. 32, n. 1, p. 9-13, 2003.

GOLDIN-MEADOW, S. The resilience of language: what gesture creation in deaf children can tell us about how all children learn language. New York: Psychology Press/Taylor \& Francis, 2003.

LANG, H.G. Perspectives on the history of deaf education. In: MARSCHARK, M.; Spencer, P.E. (Ed.). Oxford handbook of deafstudies, language, and education. New York: Oxford University Press, 2003. p. 9-20.

LEONTIEV, A. Marxism and psychological science. In: Activity, consciousness and personality. Translated by Marie J. Hall. New Jersey: Prentice-Hall, 1978. (Cap. 1).

LURIA, A.R. The child and his behavior. In: Ape, primitive man, and child: essays in the history of behaviour. Trad. Evelyn Rossiter. Sidney: Harvester Wheatsheaf, 1992. (Cap. 3; escrito em 1930).

MAYER, C.; AKAMATSU, C.T. Bilingualism and literacy. In: MARSCHARK, M.; Spencer, P.E. (Ed.). Oxford handbook of deaf studies, language and education. New York: Oxford University Press, 2003.p. 136-147.

MOURA, M.C. O surdo, caminhos para uma nova identidade. Rio de Janeiro: Revinter, 2000.

RADFORD, L.; ROTH, W.-M. Intercorporeality and ethical commitment: an activity perspective on classroom interaction. Educational Studies in Mathematics, v. 77, n. 2-3, p. 227-245, 2011.

RADFORD, L. Elementos de una teoría cultural de la objetivación. Relime - Revista Latinoamericana de Investigación en Matemática Educativa, Publicación Oficial de Investigación del Comité Latinoamericano de Matemática Educativa, n. Especial, p. 103-129, 2006.

RADFORD, L. Algebraic thinking from a cultural semiotic perspective. Research in Mathematics Education, v. 12, n. 1, p. 1-19, March 2010a.

RADFORD, L. Layers of generality and types of generalization in pattern activities. Pensamiento Númerico Avanzado, v. 4, n. 2, p. 37-62, 2010 b. 
STOKOE, W.C. Sign language structure: an outline of the visual communication system of the American deaf. Studies in Linguistics, Occasional Papers 8. Buffalo, NY: Department of Anthropology and Linguistics, University of Buffalo. Reprinted in Journal of Deaf Studies and Deaf Education, n. 10, p. 3-37, 1960/2005.

VAN DER VEER, R.; VALSINER, J. Vygotsky - uma sintese. Trad. Cecília C. Bartalotti. São Paulo: Loyola, 1996.

VYGOTSKY, L.S. Obras escogidas V- Fundamentos da defectología. Trad. Julio Guillermo Blank. Madrid: Visor, 1997. (Coletânea de artigos publicados originalmente em russo entre os anos de 1924 a 1934).

VYGOTSKY, L.S. The genetic roots of thought and speech. In: Thought and Language. Cap. 4. Edited and translated by Eugenia Hanfmann and Gertrude Vakar. Massachusets: The MIT Press, 1962.

VYGOTSKY, L.S. Pensamento e linguagem. Trad. Jefferson Luiz Camargo. São Paulo: Martins Fontes, 1998. (Originalmente publicado em russo, em 1934).

Recebido em 30 de maio de 2013.

Aprovado em 30 de setembro de 2013. 